\title{
Strategi pengembangan profesionalisme penyuluh dalam peningkatan mutu penyuluhan pertanian
}

\author{
Korespondensi \\ okeandikarya@gmail.com \\ Submit: \\ 13 Juli 2021 \\ Direvisi: \\ 27 September 2021 \\ Diterima: \\ 27 September 2021
}

\author{
R. Oke Andikarya \\ Fakultas Pertanian, Universitas Insan Cendekia Mandiri. Jl. Banten No 11 Bandung 40272, \\ Indonesia
}

\section{Abstract.}

Agricultural extension is not in accordance with the problems of farmers so that it needs to be addressed, by developing the professionalism of extension workers in improving the quality of agricultural extension. Implementation of strategic management must be able to improve the quality of agricultural extension. The research objectives are to identify and analyze: 1. SWOT of the internal environment (strengths and weaknesses) and the external environment (opportunities and challenges/threats); 2. Strategic formulation; 3. Strategic implementation; 4. Management of supervision and evaluation of the professionalism of agricultural extension workers; 5. Strategic steps to overcome problems and weaknesses. Research method with a qualitative approach.Research location: BP3K Sukalarang and Sukabumi Subdistricts, West Java. The underlying theory is educational management, strategic management, human resource management, agricultural management and extension, quality theory and culture. The research findings are: 1 . Not all BP3K heads have analyzed and combined their strengths, weaknesses, opportunities and challenges into the conclusion of strategic assumptions in the preparation of strategic plans; 2. Strategic formulation has not been based on strategic assumptions by maximizing strengths and minimizing weaknesses by taking advantage of opportunities in facing challenges. Vision, mission, strategic objectives and policies for professional development of extension workers are integrated in RENSTRA BP4K; 3. Strategic implementation includes programs, budgets and implementation procedures contained in the BP3K Annual Work Plan Program with a nominal BP3K Budget Work Plan, the agricultural extension professionalism development program has not been specifically regulated; 4. Supervision and evaluation of the professionalism of agricultural extension workers have not collaborated between the Head of BP3K and the district agricultural extension coordinator. The head of BP3K has not reported the results of the detailed and periodic professionalism assessment of agricultural extension agents to the district agricultural extension coordinator; 5. Strategies to overcome problems in an anticipatory manner through fostering motivation to all agricultural extension workers. Research recommendations: it is recommended that BP $3 K$ heads maximize strengths, minimize weaknesses, take advantage of opportunities to overcome challenges. Strategic assumptions are the basis for formulating vision, mission, goals, strategies and policies so that the professionalism of agricultural extension workers can develop to improve the quality of agricultural extension.

Keywords: strategic management, professionalism, counseling and quality of extension

\footnotetext{
Abstrak.

Penyuluhan pertanian kurang sesuai dengan permasalahan petani sehingga perlu dibenahi, dengan mengembangkan profesionalisme penyuluh dalam meningkatkkan mutu penyuluhan pertanian. Implementasi manajemen strategi harus dapat meningkatan mutu penyuluhan pertanian. Tujuan penelitian untuk mengetahui dan menganalisis: 1. SWOT lingkungan internal (kekuatan dan kelemahan) dan lingkungan eksternal (peluang dan tantangan/ ancaman); 2. Formulasi strategis; 3. Implementasi strategis; 4. Manajemen pengawasan dan evaluasi profesionalisme
} 
penyuluh pertanian; 5. Langkah strategis mengatasi masalah dan kelemahan. Metode penelitian dengan pendekatan kualitatif. Lokasi penelitian: BP3K Kecamatan Sukalarang dan Sukabumi Jawa Barat. Temuan penelitian adalah 1. Belum semua kepala BP3K menganalisis dan memadukan kekuatan, kelemahan, peluang dan tantangan menjadi kesimpulan asumsi strategik dalam penyusunan rencana strategis; 2. Formulasi strategis belum berbasis pada asumsi strategis dengan memaksimalkan kekuatan dan meminimalkan kelemahan dengan memanfaatkan peluang dalam menghadapi tantangan. Visi, misi, tujuan strategi dan kebijakan pengembangan profesionalisme penyuluh terintegrasi dalam RENSTRA BP4K; 3. Implementasi strategis meliputi program, anggaran dan prosedur pelaksanaan tertuang dalam bentuk Program Rencana Kerja Tahunan BP3K dengan nominal anggaran Rencana Kerja Anggaran BP3K, program pengembangan Profesionalisme penyuluh pertanian anggarannya belum diatur khusus; 4. Pengawasan dan evaluasi profesionalisme penyuluh pertanian belum berkolaborasi antara Kepala BP3K dengan koordinator penyuluh pertanian kabupaten. Kepala BP3K belum melaporkan hasil penilaian profesionalisme penyuluh pertanian secara rinci dan periodik kepada koodinator penyuluh pertanian kabupaten; 5. Strategi mengatasi masalah secara antisipatif melalui pembinaan motivasi pada seluruh penyuluh pertanian, Rekomendasi penelitian: para kepala BP3K disarankan memaksimalkan kekuatan, meminimalkan kelemahan, memanfaatkan peluang dalam menanggulangi tantangan. Asumsi strategi sebagai dasar penyusunan visi, misi, tujuan, strategi dan kebijakan agar profesionalisme penyuluh pertanian dapat berkembang untuk meningkatkan mutu penyuluhan pertanian.

Kata-kata kunci: Manajemen Strategi, Profesionalisme, Penyuluhan dan Mutu penyuluhan

\section{PENDAHULUAN}

Penyuluhan Pertanian dilaksanakan untuk memfasilitasi, membina, membimbing dan mendidik petani. Menurut Farguhar (1961) dalam Hawkins (1982) dalam Sugarda (2000), penyuluhan pertanian merupakan proses pendidikan dan upaya meningkatkan kemampuan petani dalam metode dan teknik usahatani dan usaha meningkatkan efisiensi produksi dan pendapatan tani, taraf hidup petani, status sosial dan tingkat pendidikan petani (Van den Ban \& Hawkins, 2003)

Penyuluhan pertanian pada dasarnya membantu petani untuk menganalisis situasi yang dihadapi dan melakukan perkiraan ke depan, menyadarkan tentang kemungkinan timbulnya masalah berdasarkan analisis, meningkatkan pengetahuan dan membantu memberikan pemahaman terhadap suatu masalah serta membantu rencana berdasarkan pengetahuan yang dimiliki petani, memperoleh pengetahuan khusus berkaitan dengan cara pemecahan masalah serta akibat yang ditimbulkannya, memutuskan pilihan secara tepat, meningkatkan motivasi untuk melaksanakan pilihan, mengevaluasi dan memperbaiki keputusan yang telah diambil dalam melaksanakan usahataninya.

Penyuluh pertanian berperan sebagai guru, penganalisis, penasihat, organisator, pengembang kebutuhan perubahan, penggerak perubahan, pemantap hubungan masyarakat petani dan kawan pemberi dorongan kerja (Mosher, 1997). Penyuluh pada masa yang akan datang harus professional karena harus menjadikan (1) Bertani yang lebih baik (better farming), (2) Berusaha tani lebih efisien (better business), (3) Lingkungan yang lebih baik (better environment), (4) Hidup lebih sejahtera (better living) serta (5) desa (masyarakat) lebih tangguh (better community).

Berdasarkan hal-hal tersebut diatas maka dikaji hal-hal yang dapat dijadikan faktor-faktor manajemen strategi dalam pengembangan profesionalisme penyuluh untuk meningkatkan mutu penyuluhan pertanian agar masyarakat lebih meyakinkan melaksanakan budidaya tanamannya, sehingga produksi dan produktivitasnya meningkat. Tujuannya untuk mengetahui dan menganalisis: 1 . SWOT lingkungan internal (kekuatan dan kelemahan) dan lingkungan eksternal (peluang dan tantangan/ ancaman); 2. Formulasi strategis; 3. Implementasi strategis; 4. Manajemen pengawasan dan evaluasi profesionalisme penyuluh pertanian; 5. Langkah strategis mengatasi masalah dan kelemahan. 


\section{BAHAN DAN METODE}

Penelitian dilakukan dengan menggunakan pendekatan kualitatif dengan metode Deskriptif dan studi kasus. Penelitian dilaksanakan pada Bulan Februari hingga Juli 2019 di dua kecamatan di Kabupaten Sukabumi, yaitu Kecamatan Kota Sukabumi dan kecamatan Sukalarang. Sedangkan lembaga yang dipilih adalah Balai Penyuluhan Pertanian, Peternakan, perikanan dan Kehutanan (BP3K). Penetapan BP3K tersebut disesuaikan dengan potensi wilayah, peta komoditas, kualifikasi penyuluh, kondisi BP3K dan Kelompok Tani. Populasi dalam penelitian adalah seluruh penyuluh pertanian PNS yang ada di dua kecamatan. Penarikan sampel menggunakan Purposive sesuai jumlah penyuluh di masing-masing kecamatan. Sampel yang dipilih sebanyak 21 orang yang terdiri dari 2 orang Kepala BP3K, 10 orang penyuluh dan 7 orang petani, 1 orang kepala BP4K, 1 orang koordinator penyuluh pertanian lapangan pada tingkat kabupaten dan 1 orang Kepala Bagian Program dan Perencanaan BP4K Kabupaten Sukabumi. Untuk menentukan manajemen strategi pengembangan profesionalisme penyuluh pertanian digunakan analisis SWOT. Proses penyusunan manajemen strategis profesionalisme penyuluh melalui faktor-faktor lingkungan strategis yaitu program penyuluhan, ketaatan dan loyalitas, budaya BP3K, jumlah penyuluh muda, profesi petani, motivasi berprestasi, kompetensi dan kemampuan penyuluh, struktur kepegawaian penyuluh, sarana dan prasarana, profesionalisme, regulasi pemerintah, kemajuan IPTEK, dukungan BP4K, uji kompetensi dan sertifikasi dan tunjangan penyuluh, akses informasi, animo petani, partisipasi penyuluh, MEA dan globalisasi, kualitas dan kepuasan petani serta produksi untuk ekspor.

Pengolahan data lapangan dilakukan dengan cara menguraikan dan mendeskripsikan data apa adanya, kemudian dianalisis berdasarkan pedoman yang sesuai dengan obyek penelitian, sedangkan analisis data dilakukan dengan langkah-langkah sebagai berikut: Data hasil observasi dan wawancara di lapangan diolah serta dideskripsikan dan dianalisis berdasarkan pedoman, studi kepustakaan dikembangkan dengan masalah dan obyek yang diteliti. Teknik pengolahan data yang dikembangkan digunakan sebagai pedoman pola pikir untuk analisis data lapangan agar meyakinkan kebenaran ilmiahnya. Sedangkan untuk memperoleh kebenarannya, peneliti mengungkapkan kenyataan-kenyataan sesungguhnya di lapangan.

\section{HASIL DAN PEMBAHASAN}

Manajemen strategi pengembangan profesionalisme penyuluh pertanian dalam peningkatan mutu penyuluhan pertanian dilihat dari faktor-faktor strategis pengembangan profesionalismenya yaitu:

\section{ANALISIS SWOT}

Tabel 1. Faktor-faktor lingkungan strategis pengembangan profesionalisme penyuluh pertanian

\begin{tabular}{|c|c|c|c|}
\hline \multicolumn{2}{|c|}{ Faktor Internal } & \multicolumn{2}{|c|}{ Faktor Eksternal } \\
\hline $\begin{array}{l}\text { Kekuatan } \\
\text { (Strenght) }\end{array}$ & $\begin{array}{c}\text { Kelemahan } \\
\text { (Weaknesses) }\end{array}$ & $\begin{array}{c}\text { Peluang } \\
\text { (Opportunity) }\end{array}$ & $\begin{array}{l}\text { Tantangan } \\
\text { (Threats) }\end{array}$ \\
\hline $\begin{array}{l}\text { 1. Programa } \\
\text { Penyuluhan } \\
\text { 2. Ketaatan dan } \\
\text { loyalitas } \\
\text { 3. Budaya BP3K } \\
\text { 4. Jumlah Penyuluh } \\
\text { Muda } \\
\text { 5. Profesi Petani }\end{array}$ & $\begin{array}{l}\text { 1. Motivasi berprestasi } \\
\text { 2. Kompetensi dan } \\
\text { kemampuan penyuluh } \\
\text { 3. Struktur } \\
\text { Kepegawaian } \\
\text { Penyuluh } \\
\text { 4. Sarana dan prasarana } \\
\text { 5. Profesionalisme }\end{array}$ & $\begin{array}{l}\text { 1. Regulasi } \\
\text { Pemerintah } \\
\text { 2. Kemajuan ipteks } \\
\text { 3. Dukungan BP4K } \\
\text { 4. Uji kompetensi dan } \\
\text { sertifikasi dan } \\
\text { tunjangan penyuluh } \\
\text { 5. Akses informasi }\end{array}$ & $\begin{array}{l}\text { 1. Animo petani } \\
\text { 2. Partisipasi } \\
\text { penyuluh } \\
\text { 3. MEA dan } \\
\text { Globalsasi } \\
\text { 4. Kualitas dan } \\
\text { kepuasan petani } \\
\text { 5. Produksi untuk } \\
\text { Ekspor }\end{array}$ \\
\hline
\end{tabular}

\section{1) Kekuatan}


Lingkungan internal lembaga dalam mengembangkan profesionalisme antara lain: adanya programa penyuluhan (desa, kecamatan dan kabupaten), karyawan dan kelompok tani cukup taat, budaya BP3K, penyuluh muda dan banyaknya masyarakat petani. Semua warga BP3K semua memahami pekerjaan, loyal, suasana kekeluargaan, memiliki program kerja dan kebijakan yang mendukung penyuluhan serta penyuluh, mengacu pada kebutuhan lapangan sesuai dengan arah kebijakan pusat (terutama pendanaan) dan daerah pembangunan pertanian. SDM penyuluh bermutu; ada kemitraan dengan perusahaan agroinput (pupuk dan pestisida); adanya metodologi penyuluhan pertanian; Komitmen penyuluh; Luas wilayah dan berpotensi yang untuk tujuan pengembangan sektor kehutanan, perkebunan dan pertanian, peternakan dan perikanan; Jumlah penduduk sebagai petani merupakan kondisi tersebut menjanjikan prospek baik, komitmen pemda dan DPRD menjadikan Kabupaten pusat pengembangan agribisnis; hubungan kerja kemitraan antara Pemda dengan DPRD dalam mengembangkan bidang pertanian

Programa penyuluhan dari tingkat desa, kecamatan dan kabupaten ada untuk merekomendasi komisi penyuluhan, yang dibiayai oleh APBD I dan APBD II.

\section{2) Kelemahan}

Kelemahan pengembangan profesionalisme penyuluh pertanian adalah motivasi berprestasi penyuluh masih rendah, kompetensi dan kemampuan serta keterampilan penyuluh pertanian masih kurang, struktur kepegawaian penyuluh PNS, Swadaya, Swasta dan THL menimbulkan disparitas kesejahteraan. Hasil penilaian profesionalisme rata-rata lemah, sarana dan prasarana kurang sehingga profesionalisme. Adanya kesenjangan antara penyuluh PNS, swasta dan swadaya dan penyuluh THL, sarana dan prasarana kurang dan pendanaan penyuluhan kurang, pengangkatan THL belum ada payung hukumnya. Penyuluh THL muda dan gesit, penghasilan antara penyuluh PNS dengan THL, penyuluh PNS disertifikasi sedangkan THL tidak, dasar pendidikan belum linier sehingga kompetensi dan profesionalisme penyuluh rendah, anggaran pengembangan profesionalisme penyuluh di setiap kegiatan dan kesejahteraan penyuluh sangat berbeda. Sebagian penyuluh pertanian belum mampu merangsang petani berfikir, penyuluh sebagai pusat pembelajaran, penyuluh belum banyak membuat media serta alat peraga penyuluhan, penyuluh sebagian besar memanfaatkan internet.

Mengikuti diklat teknis kurang; struktur organisasi dan tata kerja BP4K membutuhkan penyegaran dan penyempurnaan agar terjadi perubahan sesuai tantangan zaman; kualifikasi dan kompetensi SDM perlu peningkatan berkelanjutan; tugas pokok dan fungsi perlu disesuaikan dengan kewenangan agar sinkronisasi antara tugas pokok dan program dengan kegiatan turunannya; Tersedianya manual perencanaan dan data base perecanaan dan pengaruh model di kalangan para pejabat dan staff.

\section{3) Peluang}

Regulasi pemerintah tentang penyuluhan pertanian, kemajuan ipteks adanya internet, dukungan BP4K sebagai lembaga yang menyelenggarakan penyuluhan pertanian dan Undang-undang Nomor 16 Tahun 2006 tentang Sistem Penyuluhan Pertanian Perikanan dan Kehutanan, Uji kompetensi, sertifikasi, tunjangan penyuluh dan mudahnya akses informasi ke ilmu pengetahuan adalah peluang.

Peluang dalam pengembangan profesionalisme penyuluh antara lain: pekerjaan penyuluh sebagai profesi, penghargaan penyuluh pertanian, sertifikasi dan tunjangan profesi merupakan motivasi, para penyuluh pertanian harus menyadari pada masa sekarang dan mendatang tugasnya sangat berat.

Program uji kompetensi dan sertifikasi penyuluh dan tunjangan penyuluh, penetapan aturan tentang alih fungsi lahan sedikit menekan, serta aksesibilitas jalan menujang pembangunan pertanian. Komitmen dan keterlibatan dunia usaha swasta terhadap optimalisasi efektifitas penyuluhan.

\section{4) Tantangan}

Ketertarikan masyarakat tani untuk melaksanakan pertanian merupakan tantangan, banyaknya penyuluh yang berpartisipasi, mulai diberlakukannya Masyarakat Ekonomi Asean dan Globalisasi, mutu hasil pertanian kian baik dan petani puas dan perlu tugas serta fungsi penyuluh pertanian. Penyuluh ke depan harus dapat mengarahkan petani agar lebih terampil dan berfikir sehingga mampu mencari, menganalisa, menyimpulkan dan mempraktekkan ilmunya. Partisipasi petani ke depan, pelatihan merupakan suatu kebutuhan. 
Mengarahkan petani agar mampu berpikir adalah tantangan ke depan agar produknya bersaing dengan petani dari luar negeri: jejaring antara sesama penyuluh pertanian belum optimal, pelaku agribisnis, peneliti dan perguruan tinggi: Tingkat kepemilikan lahan usahatani relatif sempit; motivasi generasi muda untuk menekuni bidang pertanian rendah; Ethos kerja petani relatif rendah dan terbatasnya sarana produksi pertanian.

Profesionalisme adalah adalah komitmen dari para anggota profesi. Profesionalisme merupakan antisipasi menghadapi MEA dan globalisasi. Profesionalisme penyuluh nampak pada situasi dan kondisi kerja sehari-hari dan kegiatan menjalankan tugas, cara serta mutu kegiatan penyuluhan. Profesionalisme penyuluh ada tiga aspek yang menjadi dasar kriteria, yaitu 1) tingkat kehadiran penyuluh rata-rata 95100\%: 2) administrasi penyuluhan (silabus dan programa), analisis proses penyuluhan dan evaluasi lengkap, penyuluh diberi dana dan fasilitas kendaraan, 3) tugas pokok penyuluh cukup sampai baik.

Mutu penyuluhan di lapangan dapat membangun kepercayaan petani. Kualitas pelayanan diketahui dengan cara membandingkan kepuasan petani atas layanan yang diterima dengan yang mereka harapkan (Parasuraman et al. dalam Nasution (2001) dalam Abubakar dan Siregar, (2010)): 2). Percontohan dibuat pada setiap daerah dan dilakukan dengan komunikasi yang efektif, penyuluhan bermutu dan sesuai dengan kondisi wilayah dan budaya masyarakatnya.

Kemampuan teknis penyuluh harus polyvalen. Instansi yang membidangi penyuluhan harus mengupayakan pelatihan komunikasi, lobi dan negosiasi. Budaya disesuaikan dengan visi, misi dari lembaga, nilai agama yang ditaati oleh seluruh warga: 1) Disiplin petani menjalankan agama, 2) Penyuluhan dilakukan di lapangan/kebun tempat petani berusaha atau di masjid, 3) Memperkenalkan teknologi dan nilai-nilai kehidupan yang modern dan rasional.

\section{FORMULASI STRATEGI}

\section{1) Pernyataan Misi}

Pernyataan misi pengembangan profesionalisme penyuluh yaitu: Visi: Terwujudnya penyuluhan pertanian, perikanan dan kehutanan yang profesional maju dan tangguh. Misinya: Mengembangkan sistem pemberdayaan pelaku utama, kelembagaan tani yang berdaya saing; Mengembangkan sistem pelatihan manajemen, kepemimpinan, kewirausahaan dan teknis agribisnis yang andal; Meningkatkan kualitas SDM pertanian, perikanan dan kehutanan; Meningkatkan percepatan penyerapan dan penerapan teknologi pelaku utama dan usaha berbasis cyber extension; dan Mengembangkan sistem administrasi dan manajemen transparan dan akuntabel.

Misi belum semua menyadari dan memahami untuk dijalankan dan motivasi belum meningkatkan mutu penyuluhan. Misi dituangkan dalam Rencana Strategis (Renstra) Kabupaten, berisikan analisis SWOT lingkungan internal eksternal; visi, misi, tujuan, strategi dan kebijakan; implementasi berupa program kerja, program anggaran dan pelaksanaan; serta pengawasan, evaluasi serta tindak lanjut.

\section{2) Tujuan}

Batasan pencapaian terhadap pernyataan misi pengembangan profesionalisme penyuluh, yaitu. tercapainya suatu kondisi penyuluh memiliki kompetensi dan profesional. Tujuan jangka menengah dan pendek diarahkan agar penyuluh mampu sebagai pengajar yang mengarahkan dan mendorong petani untuk berpikir, pendidik mampu menanamkan nilai/norma sehingga mutu penyuluhan menjadi lebih baik. Tujuan jangka pendek diarahkan agar penyuluh terampil mengajar, memberikan ketauladanan serta memberikan keterampilan hidup bagi petani, mengelola kegiatan penyuluhan pertanian yang terpadu, efektif dan efisien, sehingga mutu penyuluhan menjadi lebih baik.

\section{3) Strategi}

Penyuluh mampu memberikan penyuluhan agar petani terampil; penyuluh memberikan teladan dan menanamkan norma sosial. Strateginya adalah Revitalisasi kelembagaan tani; Revitalisasi ketenagaan Lingkup Petani; Revitalisasi Penyelenggaraan; Revitalisasi Kerjasama dan Infoteker (Pengembangan 
jejaring kerjasama antara pelaku utama dengan pelaku usaha, Peningkatan kuantitas dan kualitas diseminasi teknologi tepat guna dan Pengembangan cyber sebagai basis diseminasi teknologi; Revitalisasi Manajemen dan Administrasi Pendidikan.

\section{4) Sasaran}

Sasaran adalah bergabungnya seluruh pelaku utama, pengelolaan lembaga penyuluhan di tingkat desa dan kecamatan, kemampuan kelembagaan tani meningkat, terwujudnya kelembagaan tani menjadi lembaga ekonomi pedesaan, meningkatnya kinerja, kompetensi dan kreativitas penyuluh pertanian, profesionalisme kinerja penyaluh.

Penyuluhan mendukung Program Utama Pembangunan Pertanian. Penyuluhan partisipatif, mewujudkan diseminasi teknologi tepat guna spesifik lokalita, diseminasi teknologi melalui cyber extension, pengkajian teknologi tepat guna, terjalin kerjasama antar pelaku utama, balai penelitian dan pelaku usaha, dan dukungan sarana dan prasarana penyuluhan.

\section{5) Kebijakan}

Kebijakan pengembangan profesionalisme penyuluh mengacu pada kebijakan dan Undang-undang Nomor 16 Tahun 2006 diantaranya menyangkut standar pendidikan, kompetensi, sertifikasi, pedoman penilaian penyuluh dan aturan kepegawaian lainnya. Untuk mencapai profesionalisme penyuluh pertanian meliputi : kompetensi dan kemampuan penyuluh; pengembangan keprofesian berkelanjutan; penilaian kinerja; dan pengembangan budaya.

\section{IMPLEMENTASI STRATEGI}

\section{1) Program}

Pengembangan profesionalisme penyuluh masih terbatas pada Program pembinaan supervisi lapangan dan manajemen penyuluhan serta penilaian penyuluhan bagi penyuluh PNS tersertifikasi; pengembangan kompetensi dan profesionalisme penyuluh lebih banyak mengikuti diklat yang diadakan pemerintah, karena keterbatasan dana dan harmonisasi.

\section{2) Anggaran}

Pendanaan, setiap program belum sepenuhnya dilaksanakan, karena anggaran lembaga penyuluhan tingkat kecamatan belum memadai, per tahun hanya Rp. 38.000.000,- (biaya maintenance kantor, kegiatan penyuluhan Rp. 3.000.000 per kegiatan penyuluhan. Biaya uji lapangan Rp. 1.400.000,-. Biaya Opersional Pusat (BOP) Rp. 320.000,- per satu penyuluh. Bayar honor penyuluh Rp.420.000,- dari pusat per bulan, Rp. 250.000,- dari provinsi dan Rp. 450.000,- dari kabupaten. Sedangkan honor penyuluh yang belum tersertifikasi, diberi honor berdasarkan jumlah penyuluhan dan tunjangan penyuluhan.

\section{3) Prosedur}

Peningkatan kompetensi dan profesionalisme penyuluh dilakukan melalui diklat dari Dinas Pertanian Kabupaten, Provinsi atau Pusat Penyuluhan Kementerian Pertanian, Balai Pengkajian Tanaman Pertanian, serta IHT lembaga penyuluhan. Peningkatan keterampilan dilakukan melalui supervisi lapangan.

\section{PENGAWASAN DAN EVALUASI}

Monitoring dan evaluasi pengembangan profesionalisme penyuluh dilakukan dalam rapat dinas bulanan dengan mengundang kepala lembaga penyuluhan kecamatan. Evaluasi pengembangan profesionalisme penyuluh pertanian belum sepenuhnya dilakukan karena terkait anggaran. Penilaian profesionalisme penyuluh pertanian terbatas pada penyuluh berprestasi. Dokumenya adalah laporan kegiatan penyuluhan di lapangan. Penyuluh yang professional bertanggungjawab terhadap kinerjanya. Evaluasi dilakukan pada awal perencanaan, sedang dan akhir kegiatan penyuluhan pertanian. Sedangkan evaluasi pengembangan profesionalisme penyuluh dilakukan setiap tahun oleh bidang ketenagaan penyuluhan dan oleh jabatan fungsional dalam bentuk evaluasi kinerja bidang dan pegawai, karena fasilitasi anggaran dan SDM staf dan penyuluh itu sendiri. Evaluasi pengembangan profesionalisme 
kinerja penyuluh sebetulnya sebagai bentuk pertanggungjawaban terhadap biaya operasinal penyuluh pertanian.

\section{1) Perencanaan Pengawasan}

Perencanaan pengawasan dituangkan dalam program supervisi lapangan dan terjadwal selama satu semester, unsur-unsur yang disupervisi menyangkut: kelengkapan administrasi perencanaan penyuluhan (program penyuluhan, silabus, buku sumber, alat evaluasi dan sebagainya); pelaksanaan penyuluhan dimulai dari pembukaan, kegiatan inti, dan menutup penyuluhan dan evaluasi, analisis dan tindak lanjut hasil penilaian. Perencanaan pengawasan dan evaluasi dilakukan oleh kepala BP4K dan kepala BP3K.

\section{2) Pelaksanaan Pengawasan}

Penilaian profesionalisme penyuluh pertanian diatur oleh Kementerian Pertanian dan dilaksanakan pada penyuluh PNS. Profesionalisme penyuluh dilaksanakan melalui pemeriksaan administrasi penyuluhan, kumulatif kehadiran dan hasil supervisi kunjungan lapangan kepala BP4K dan BP3K. Unsur yang termasuk penilaian adalah perencanaan penyuluhan, proses penyuluhan dan hasil penyuluhan. Pengawasan dan evaluasi profesionalisme penyuluh dilakukan melalui supervisi lapangan yang diprogramkan dalam proses penyuluhan pertanian sehingga penyuluhan lebih bermutu sesuai dengan standar proses penyuluhan. Supervisi lapangan yaitu kunjungan ke lapangan langsung secara mendadak dan mengidentifikasi kekurangan atau kelemahan penyuluh pertanian dalam proses penyuluhan; Kedua, merumuskan kekurangan penyuluh pertanian dan mendiskusikan rencana pembinaannya; Ketiga, pelaksanaan pembinaan supervisi lapangan secara kolektif; Keempat, adalah profesionalisme untuk mengukur pembinaan berhasil atau tidak. BP3K melaksanakan pertemuan dua mingguan untuk meningkatkan kapasitas penyuluh pertanian monitoring.

Supervisi, setiap dua minggu penyuluh pertanian profesional membuat rencana penyuluhan, media alat peraga penyuluhan, menyiapkan materi penyuluhan, melakukan penilaian hasil penyuluhan dan melakukan proses penyuluhan, sebagai bahan masukan dalam pembinaan profesionalisme penyuluh. Penilaian profesionlisme penyuluh menggambarkan keberhasilan pembinaan dan supervisi sesuai target BP4K.

\section{3) Evaluasi dan Tindak lanjut}

Evaluasi program pengembangan profesionalisme penyuluh pada dasarnya adalah pengontrolan terhadap program di akhir program. Sedangkan evaluasi terhadap hasil akhir berupa out-put dan outcome, hasil kerja penyuluh pertanian dalam meningkatkan mutu penyuluhan. Tindakan evaluasi profesionalisme adalah analisis oleh kepala BP4K dan rekomendasi koordinator penyuluh pertanian dan Evaluasi selanjutnya dengan melihat daftar hadir. Dalam Peningkatan kemampuan dan keterampilan penyuluh dilakukan pelatihan. Sedang secara kuratif dilakukan penanganan masalah setelah muncul kendala. Dalam pengembangan profesionalisme penyuluh adalah lembaga penyuluhan belum memiliki konsultan pengembangan SDM.

\section{LANGKAH-LANGKAH STRATEGI MENGATASI MASALAH}

\section{1) Masalah}

Kelemahan penyuluh adalah motivasi dalam menjalankan programa penyuluhan dan kemampuan serta keterampilan yang masih belum mumpuni, belum terbiasa menggunakan pendekatan ilmiah dan jarang melatih berani untuk berpikir, penyuluhan masih belum banyak menggunakan media dan peraga penyuluhan. Motivasi berprestasi berkurang karena disparitas penghasilan di lingkungan BP3K, kreatifitas penyuluh kurang dalam pembuatan media penyuluhan, alat peraga penyuluhan kurang dan penyuluh tidak linear dalam latar akademik dengan penyuluhan.

\section{2) Strategi Mengatasi Masalah}

Penanganan masalah secara kuratif direkomendasikan ke dalam program workshop dan IHT. Strategi mengatasi masalah antara lain dengan memfasilitasi anggaran, pengangkatan PNS baru dan pengangkatan THL. 


\section{3) Kecenderungan Penyuluh ke depan}

Kecenderungan penyuluh dalam upaya meningkatkan mutu penyuluhan yaitu selalu menyiapkan rencana penyuluhan dengan metode yang mendorong petani aktif menerapkan; mencoba mempraktekkan di kebunnya dan lain-lain.

\section{LANGKAH KE DEPAN}

Peningkatkan profesionalisme penyuluh pertanian dilakukan dengan mendorong motivasi penyuluh. mengembangkan program Penilaian Profesinalisme Penyuluh dan Pengembangan Keprofesian Berkelanjutan (PKB) penyuluh. Penyuluh yang berlatar belakang bukan dari bidang penyuluhan pertanian diperbaiki melalui pelatihan.

\section{NILAI BUDAYA}

Iklim budaya menjadi karakteristik lembaga dengan garis pokok sebagai berikut: menggali kebenaran ilmu pengetahuan; berupaya menanggapi perkembangan sosial budaya; Implementasi pengembangan budaya lembaga. Lembaga penyuluhan belum menjadikan nilai yang dikembangkan dituangkan dalam bentuk peraturan yang dipahami, dimengerti, diyakini, dirasakan dan dijalankan.

\section{SIMPULAN}

Manajemen strategik pengembangan profesionalisme penyuluh dalam peningkatan mutu penyuluhan pertanian terintegrasi dengan Rencana Strategik (RENSTRA) BP4K, dituangkan dalam Rencana Kerja BP4K dan diimplementasikan dalam Rencana Kerja Anggaran BP4K. Faktor kekuatan, kelemahan, peluang dan tantangan hasil analisis SWOT belum dipadukan menjadi asumsi strategi sebagai dasar penyusunan visi, misi, tujuan dan strategi manajemen pengembangan profesionalisme penyuluh. Implementasi strategi berupa penyusunan program, penetapan anggaran dan prosedur pelaksanaan belum maksimal. Ukuran faktual profesionalisme penyuluh adalah ketika mampu meningkatkan mutu penyuluhan pertanian yaitu: membentuk petani unggul, berpengetahuan dan terampil, mampu berpikir serta menggali potensi dan berdaya saing.

Analisis SWOT lingkungan strategi pengembangan profesionalisme penyuluh dalam peningkatkan mutu penyuluhan pertanian, kekuatan meliputi: programa penyuluhan, ketaatan dan loyalitas, iklim budaya kondusif, jumlah penyuluh muda usia produktif dan dukungan dana BOP dari pemerintah pusat. Kelemahan meliputi: rendahnya motivasi berprestasi, perbedaan kepegawaian, kompetensi dan kemampuan dalam menyuluh, sarana prasarana. Peluang meliputi: Regulasi pemerintah, kemajuan iptek, dukungan BP4K dan Pemda, uji kompetensi dan sertifikasi penyuluh pertanian, akses informasi kurang maksimal serta standar penyuluhan. Tantangannya adalah: animo masyarakat terhadap penyuluhan pertanian, partisipasi penyuluh pertanian PNS cenderung menurun, tuntutan MEA dan globalisasi, mutu penyuluhan kurang, Kepala BP3K belum menganalisis dan memadukan kekuatan, kelemahan, peluang dan tantangan menjadi asumsi strategi sebagai dasar penyusunan rencana strategi.

Formulasi startegi pengembangan profesionalisme penyuluh pertanian dalam peningkatkan mutu penyuluhan belum berbasis pada asumsi strategi dengan memaksimalkan kekuatan dan meminimalkan kelemahan, memanfaatkan peluang dalam menghadapi tantangan. Visi, misi, tujuan, strategi, sasaran dan kebijakan terintegrasi dalam RENSTRA BP4K dengan tujuan: penyuluh berkemampuan dan berketerampilan menyuluh, mengembangkan budaya BP3K serta berketerampilan lapangan.

Implementasi strategi meliputi program, anggaran dan prosedur pelaksanaan dituangkan dalam Program Rencana Kerja Tahunan BP4K dan Rencana Kerja Anggaran BP3K dengan sistematika penyusunan dan indikatornya ditentukan pemerintah. Pengembangan profesionalisme penyuluh, anggarannya belum diatur khusus tetapi terpilah-pilah dalam setiap kegiatan penyuluhan pertanian. Penilaian Profesionalisme Penyuluh dan Pengembangan budaya BP3K pelaksanaan tercantum dalam rincian kegiatan masing-masing. 
Pengawasan dan evaluasi penyuluh pertanian belum berkolaboratif dengan pihak lain dan berjalan secara maksimal, kepala BP3K belum melaporkan hasil kunjungan lapangan hasil penilaian profesionalisme penyuluh secara rinci dan periodik kepada kepala BP4K. Koordinator penyuluh melaksanakan penilaian profesionalisme pada penyuluh PNS saja.

Masalah pengembangan profesionalisme penyuluh untuk meningkatkan mutu penyuluhan pertanian menyangkut; motivasi berprestasi, kesenjangan kesejahteraan, status kepegawaian penyuluh, kompetensi pedagogik dan kemampuan menyuluh. Strategi mengatasi masalah secara antisipatif melalui pembinaan seluruh penyuluh; pengembangan budaya BP3K dan pelatihan penyuluhan pertanian Sedangkan secara kuratif dilakukan melalui: Pemberian reward, dan Pengembangan Keprofesian Berkelanjutan.

Langkah-langkah Mengatasi Masalah meliputi, strategik mengatasi masalah, kecenderungan penyuluh ke depan, langkah ke depan dan nilai budaya. Masalah pengembangan profesionalisme penyuluh untuk meningkatkan mutu penyuluhan menyangkut: motivasi berprestasi, kesenjangan kesejahteraan, status kepegawaian penyuluh, kompetensi dan kemampuan menyuluh dan hasil penilaian profesionalisme. Secara antisipatif dilakukan pembinaan dan dorongan motivasi. Kelemahannya profesionalisme diberlakukan hanya pada penyuluh PNS, sedangkan sebagian besar penyuluh PNS mau memasuki usia pensiun, sarana dan prasarana kurang memadai dan anggaran kurang mencukupi. Pengembangan budaya tertuang dalam enam sistem nilai kehidupan yaitu teologis, logis, etis, estetis, physik dan teleologis, pelatihan/ IHT, workshop dan supervisi. Sedangkan secara kuratif memberikan reward dan Pengembangan Keprofesian Berkelanjutan yang didanai Pemerintah Daerah melalui Dinas Pertanian.

Analisis lingkungan internal dan eksternal dalam pengembangan profesionalisme penyuluh melalui SWOT meliputi memadukan kekuatan (strength), kelemahan (Weakness), peluang (Opportunity), dan tantangan/ancaman (Threat) dihasilkan asumsi strategi. Pilihan asumsi strategi bisa dijadikan dasar penyusunan visi, misi, tujuan, strategi dan kebijakan dalam pengembangan profesionalisme penyuluh pertanian

Implementasi strategi pengembangan profesionalisme penyuluh, dibuat program berdasarkan kebijakan BP3K, tidak bertentangan dengan kebijakan BP4K dan Pemda, kebijakan Pemerintah Pusat dan Provinsi, dan disesuaikan dengan alokasi anggaran yang tersedia. Upaya mengembangkan kompetensi pedagogik dalam memahami karakteristik dan kemampuan petani, kepala BP3K memfasilitasi lapangan secara khusus dalam mengklinis petani.

Dalam pengembangan budaya BP3K yang berlandaskan enam nilai (teologis, fisiologis, logis, etis, estetis dan teleologis) diimplimentasikan dalam bentuk Peraturan BP3K. Pengaruhnya yang diharapkan terciptanya budaya malu, disiplin, jujur dan bermutu. Dibuatkan regulasi penerapan dan pengembangan budaya organisasi sebagai pedoman pembinaan tani dalam bentuk peraturan BP3K yang menginternalisasi nilai-norma agama, falsafah Pancasila, dan nilai kearipan lokal kepada petani.

\section{DAFTAR PUSTAKA}

Juhaedi, A. (2016). Profesionalisme Penyuluh. ajatjuhaedi.blogspot.com/profesionalisme-penyuluh. [diakses pada tanggal 17 September 2021].

Mosher A. T. (1997). An Introduction to Agiculture Extension. Agriculture Departement Council. New York.

Sugarda T. J. (2000). Penyuluhan Pertanian. Kerjasama dengan Yayasan Pengembangan Sinar Tani. Bandung

Undang-Undang Nomor 16 tahun 2006. Sistem Penyuluhan Pertanian, Perikanan dan Kehutanan. Kementerian Pertanian, Jakarta.

Van den Ban, A. W. \& Hawkins, H. S. (2003). Penyuluhan Pertanian. Kanisius. Yogyakarta. 